\title{
Identidade e consumo na pós-modernidade: crise e revolução no marketing
}

"Em nenhum de meus trabalhos anteriores tive, tão forte quanto agora, a impressão de que o que estou descrevendo pertence ao conhecimento comum e de que estou desperdiçando papel e tinta, ao mesmo tempo que usando o trabalho e o material do tipógrafo e do impressor para expor coisas que na realidade são evidentes por si mesmas."

- Sigmund Freud, O Mal-Estar na Civilização

\section{RESUMO}

Neste artigo, o autor discute uma crise de paradigmas e uma nova visão mercadológica do consumo. A forma como consome mudou, assim, ao menos, sentenciam os doutrinadores pós-modernos, os mesmos que decretaram a crise do marketing.

\section{PALAVRAS-CHAVE}

- consumo

- paradigma

- pós-modernidade

\section{ABSTRACT}

In this article the author discusses the consumption transformations, a crisis of paradigms and a new vision of market. The consumer changed. Consequently, also, the form how it consumes - as the post-modern thinkers say, the same ones that decreed the crisis of the marketing.

\section{KEY WORDS}

- consumption

- paradigm

- post-modernity
D o consumo à consumação. O consumidor mudou! Alerta pós-moderno. Afetado por um novo mundo, recusou-se a permanecer. Esse novo ser definido por esse novo discurso é o objeto do nosso estudo. A emergência de problemas - que não encontram soluções nos antigos fundamentos e pressupostos compartilhados pela doutrina oficial começa a ser denunciada por importantes autores. ${ }^{1}$ A produção propriamente acadêmica sobre $o$ assunto é ainda escassa. Mas o sentimento dessas dificuldades já é manifesto no discurso de profissionais.

Eis o nosso objeto. Esse discurso preocupado. Impaciente. Análise de um discurso de crise, portanto. Investigamos os interesses de seus porta-vozes, os troféus que disputam. Discurso socialmente construído. Politicamente estratégico. Crítica a uma crise anunciada. Quanto aos colegas acadêmicos especializados em marketing, serão citados na medida de sua pertinência.

O corpus de nossa pesquisa faz desfilar as crenças de múltiplos autores. Todos autorizados a manifestálas. Mas distintamente legitimados para convertêlas em juízo hegemônico. Os fundamentos para a crise raramente extrapolam a própria experiência. ${ }^{2}$ A essa intuição profissional, justapõe-se uma transição conceitual. Dois dos principais efeitos de uma crise científica, apontados por Thomas Kuhn, vão sendo evidenciados: o antigo paradigma ${ }^{3}$ é obscurecido progressivamente, resultando num relaxamento das regras que orientam as pesquisas dessa área. Numa flexibilização da própria ciência nor$\mathrm{mal}^{4}$ do marketing. Assiste-se ao surgimento ininterrupto de novas versões de como se trabalhar com os problemas mercadológicos.

Transformações na produção científica. Fenômeno social que exige investigação sociológica. Buscam-se causas também sociais. Afinal, de que universos sociais estamos falando? O campo científico, que tem o marketing por objeto, deixa-se afetar, com maior ou menor intensidade, pelo próprio universo sócio-profissional da sua aplicação. Sua produção denuncia impasses. ${ }^{5}$ Métodos científicos e quadros conceituais de referência nem sempre garantem a soberania acadêmica ante as "simples" pesquisas de mercado.

Todo campo de produção cultural será tanto mais puro quanto mais seus agentes dedicarem-se exclusivamente a suas atividades correspondentes, científicas ou artísticas. Assim, a presença de agentes dúbios, que ocupam com um pé posição no campo de produção do conhecimento científico e, com outro, posição em universos consagrados à aplicação 
desses conhecimentos, revela carências de estruturação desses espaços e pouca autonomia recíproca.

Essa crise é, assim, agravada pelo caráter heterônomo desse campo. ${ }^{6}$ Ciência ou estratégia de lucro? A indefinição sobre o papel do marketing resulta numa batalha travada por agentes com capitais distintos: ${ }^{7}$ científicos $^{8}$ e não-científicos. Profissionais do mercado e acadêmicos dividem e intervêm na estrutura desse campo, dificultando a consolidação de saber unificado numa só doutrina. Diferentes são as perspectivas; discrepantes os critérios para se separar o argumento legítimo do ilegítimo: lógica científica ou lógica do lucro?

Uma análise dicotômica. Um texto em duas partes: a primeira, porque é preciso começar Target: a crise de um velho paradigma - a gênese e a lógica das teorias embasadas nos grupos de referência: as razões de seu sucesso em décadas passadas e os problemas que apresentam hoje (I); a segunda, Meeting Points: ${ }^{9}$ a emergência de um novo paradigma - uma nova forma (gestalt) de abordar o marketing (II).

\section{Target: a crise de um velho paradigma}

Poucas são as expressões com tanta freqüência no jargão mercadológico quanto target $^{10}$. "O nosso target é esse." "Nosso produto é inadequado para tal target." "A categoria x está fora do target visado." Seu uso é indiscriminado. Não há briefing ${ }^{11}$ sem ele. Sua relevância para área é, ainda hoje, evidente. Percebe-se que esse conceito é recorrente não só nas agências publicitárias e nos departamentos de marketing dos anunciantes, como também na literatura especializada. Não há livro de marketing que o ignore. Os doutrinadores enfatizam sua importância em volumosos manuais. ${ }^{12}$ Cuja memorização é zelosamente cobrada por subservientes professores. Professores de marketing.

O conceito de target, entretanto, enseja um enfoque muito particular de consumo. Indiscutível para muitos, ${ }^{13}$ mas já criticada por outros tantos. Resistências ancoradas na pós-modernidade. Para mais aguda compreensão, duas sub-partes: (A) - Consumo e identidade na modernidade, a ascensão das teorias do target e a relação dessas com a maneira moderna de ver e interpretar o mundo e (B) Consumo e identidade na pós-modernidade, as dificuldades que o mundo pós-moderno impõe a essas teorias.

\section{Consumo e identidade na modernidade}

Max Weber caracteriza essa modernidade por um "desencantamento do mundo". Se antes dela, esse último era explicado por forças ocultas, passou a sêlo racionalmente. Segundo Marilena Chaui:

A modernidade teria privilegiado o universal e a racionalidade; teria sido positivista e tecnocêntrica, acreditado no progresso linear da civili- zação, na continuidade temporal da história, em verdades absolutas. ${ }^{14}$

Diante dessa nova forma de perceber e interpretar o real, e face às novas tecnologias de produção desenvolvidas na revolução industrial, houve grande mudança no processo social do trabalho ${ }^{15}$. O planejamento da produção econômica é um de seus efeitos mais visíveis.

Com isso, por muito tempo as organizações capitalistas se voltaram para a racionalização dos custos e da produção. Foi somente com a grande crise de 29 que essa antiga concepção entrou em colapso. Novos padrões de produção foram, então, estabelecidos - dentre eles o fordismo. Mas certamente - para o objeto de nossa análise - o que de mais interessante aconteceu nesse período foi o surgimento de uma forma original de abordar o consumo, que passou a iluminar a antes obscurecida demanda. O consumidor e suas necessidades tornaram-se, então, o novo centro gravitacional do sistema capitalista: nascia o marketing.

Teorias para explicar o comportamento do consumidor pipocaram nesse momento. Do behaviorismo à psicanálise. Diversas escolas enfrentaram-se. $\mathrm{O}$ marketing estava em seu período pré-paradigmático. Mas só com o fim do marketing de massa, muito intensificado nos anos cinqüenta - graças à consolidação dos meios de comunicação coletiva -, a expressão target ganhou força. O mercado passou, então, a ser dividido em segmentos homogêneos, uniformes e coerentes. ${ }^{16}$ Surgiram os grupos de referências. E o marketing ganhava a fisionomia que ainda hoje possui para muitos profissionais e autores.

Vários critérios ao longo dos anos permitiram estabelecer tais grupos. Perfis demográficos, de comportamento, psicográficos e até geográficos. Sobre esses últimos, Pierre Bourdieu ${ }^{17}$ pondera que:

Para compreender mais completamente as diferenças de estilo de vida entre as diferentes frações de classes sociais - particularmente em matéria de cultura - seria preciso levar em consideração sua distribuição num espaço geográfico socialmente hierarquizado - como os diferentes bairros de uma cidade. De fato, as chances que um grupo pode ter de se apropriar de bens raros (e que dão fundamento às esperanças matemáticas de acesso) dependem, por um lado, de suas capacidades de apropriação específicas, definidas pelo capital econômico, cultural e social que podem disponibilizar para se apropriar materialmente e/ou simbolicamente dos bens considerados. Dependem, por outro lado, da relação entre sua distribuição no espaço geográfico e a distribuição dos bens raros neste espaço - relação que pode se medir em distâncias médias para alcançar bens e equipamentos, 
ou em tempo de deslocamento - o que faz intervir o acesso a meios de transporte, individuais ou coletivos.

A distinção, desse mesmo autor, já sugeria, desde os anos 70, um padrão de consumo a partir da combinação de três capitais elementares: o social, o cultural e o econômico. ${ }^{18} \mathrm{O}$ consumo seria, então, a objetivação de uma espécie de habitus ${ }^{19}$ social adquirido por alguém com tais e tais capitais. A manifestação de certos esquemas ou disposições permanentes de classificação do mundo incorporados em determinadas condições objetivas de existência, na sua trajetória social.

Há uma tendência, sobretudo da psicologia do comportamento, em circunscrever a identificação dos efeitos de uma mensagem publicitária qualquer ao instante da recepção da mensagem. Essas explicações ignoram que o consumidor, enquanto agente de consumo, encontra princípios explicativos de sua ação num acúmulo de disposições e de esquemas interiorizados de interpretação do real que lhe faculta a identificação dos efeitos sociais reclassificadores que esta ou aquela aquisição determina.

$\mathrm{O}$ agente social que consome, enquanto dotado de um habitus, é um individual coletivo ou um coletivo individuado, pela incorporação de estruturas objetivas que permitem a atribuição de sentido e valor a qualquer ato de consumo, bem como a qualquer coisa ou serviço consumido.

Desta forma, o habitus de um consumidor garante-lhe a exegese social de qualquer oferta, isto é, a possibilidade de antecipar, sem consciência da antecipação, os efeitos sociais, estruturados e estruturantes, de qualquer aquisição. Esclarecemos que esse habitus de consumo nada tem de princípio mecânico de ação ou de reação, no sentido de reflexo. É espontaneamente condicionado e limitado. Trata-se de um princípio autônomo que faz com que a decisão de consumir não seja simplesmente uma reação imediata a uma realidade bruta, mas uma resposta "inteligente" a um aspecto ativamente selecionado do real em oferta.

A distância que o habitus do consumidor introduz entre o estímulo de qualquer oferta objetiva e a reação consumidora é uma distância de tempo, à medida que, originário de uma história, ele é relativamente constante e durável. É produto de experiências passadas e de um acúmulo coletivo e individual que só pode ser compreendido adequadamente por uma análise genética que se aplica ao mesmo tempo à história individual e à história coletiva. História específica de um universo determinado. De um campo social específico, onde um habitus singular de consumo se forja. Onde se encontram os agentes de determinadas práticas de consumo.

O consumo como sistema de propriedades - que determina a posição ocupada no campo das lutas de classes e que é determinado por ela - só pode ser entendido a partir da posição ocupada pelos consumidores num universo social. Tendo, assim, seu peso relativizado de um campo a outro.

Foi somente com uma tendência dos anos noventa, o marketing direto, que se começou a revelar as dificuldades e limitações que o antigo paradigma já abrigava. Para superar anomalias, que frustravam as expectativas de se identificar um padrão de consumo estabelecido pela posição ocupada pelo consumidor na estratificação social, o marketing tornou-se individual. ${ }^{20}$

\section{Consumo e identidade na pós-modernidade}

Oito horas. Quinze minutos. Seis de agosto. Do ano de 1945. Ano de Nosso Senh.....Booooom! A matéria se desintegra em energia. O grande cogumelo engole Hiroshima. Com ela, a crença na razão. Na esquizofrenia dualista que lhe outorgava soberania ante o corpo. Na fronteira entre o cogito e o extenso. Nas explicações totais: totalizantes e totalitárias. No desencanto. Na contenção. Na poupança e no consumo. Num Deus único. Nos imperativos e responsabilidades categóricos. No respeito à solidez dos discursos identitários.

Enquanto isso, no outro lado do mundo, em lugar incerto, quiçá no império do efêmero, "a panela deixa de ser simplesmente um lugar para cozer alimento e ganha status de objeto de arte".21 Triunfo do design. Hecatombe do funcional. Nasce a pós-modernidade ou pós-modernismo. ${ }^{22}$ Símbolo de uma nova era. ${ }^{23}$ Era do vazio. De um novo entendimento. De "revanche dos valores do sul".24 "De retorno histórico e pendular ao predomínio do sensorial em detrimento do racional".25 De sensualismo pósmoderno. De explicações compreensivas e fragmentadas. De reencanto. De excesso. De desperdício e de consumação. De muitos deuses. E da parte do diabo. De crepúsculo do dever. De maior respeito à liquidez dos amores. Da natureza oscilante dos afetos.

Tudo rápido demais. Nascitura ainda sem nome. Um nome dado às pressas. ${ }^{26} \mathrm{Um}$ pós qualquer coisa. ${ }^{27}$ Para o que vem depois do que acaba de acabar. Sem mais delongas. Sem preocupações com a própria substância. Definição pelo outro. ${ }^{28}$ Apenas o que não é. Ou o que não é mais. $\mathrm{O}$ vivo pelo morto. ${ }^{29}$ Denúncia do fluxo. Pleonasmo. Pós-modernidade, portanto. ${ }^{30}$

Se a modernidade se caracterizou pela tentativa de entender objetivamente os poderes que formam o tecido social, em grandes recortes da realidade, a pós-modernidade, por sua vez, denuncia os micropoderes capilares que a compõem. Assim,

se a modernidade trabalhava com grandes categorias como o indivíduo e o homem (no liberalismo) ou as classes sociais (no socialismo e 
no comunismo) ou o homem e os movimentos sociais (no anarquismo), a pós-modernidade fala nas pessoas, cuja identidade importa pouco porque seu ser é dado pelo sistema de diferenças que cria a alteridade ou o "outro": mulheres, homossexuais, negros, índios, crianças, idosos, sem-teto, religiosos. ${ }^{31}$

Destarte, a participação em projetos sociais do homem pós-moderno é, segundo seus teóricos, orientada para pequenos objetivos pragmáticos e/ou personalizados. As atribuições tornam-se múltiplas. Mediações determinadas pelo pertencimento a esta ou aquela classe social perdem fertilidade explicativa quando tribos, famílias, etnias, gêneros, profissões e instituições apresentam suas próprias formas de mediação simbólica, com seus papéis específicos. ${ }^{32} \mathrm{Nes}-$ se sentido, di Nallo denuncia a irredutibilidade a um critério unitário de classificação das diferenças, pluralidade de corporações funcionais não necessariamente orientadas para princípios universalistas e não necessariamente manifestantes Gemeinshaft, cada sujeito está envolvido com muitas densificações sociais não mais mediadas por uma estrutura unificadora e não pedindo mais de uma vida nem o espaço de uma função. ${ }^{33}$

Também Deleuze e Guattari propõem a desconstrução dos grandes sistemas castradores (sindicatos, família, escolas) e de seus centros de comando, para que, assim, o homem deixe de ser mera máquina a serviço da eficácia - e liberte sua energia do lucro e a oriente para o pleno gozo. Esquizoanálise. Para quando a psicanálise tropeça. Para quando as ideologias parecem tudo explicar. ${ }^{34}$ Sistema capitalista a ser desconstruído. Por meio de uma revolução molecular.

No entanto, o homem pós-moderno está programado demais para tal revolução, reconhecem outros, menos esperançosos..$^{35}$ Sua participação nessas causas é geralmente branda e frouxa, volátil. Bem diferente dos antigos militantes e suas eternas bandeiras de luta. ${ }^{36}$ Grupos muito fechados com fronteiras simbólicas nítidas, objetivadas em altos custos de entrada e defecção e que pretendem fazer assimilar as identidades de seus membros à da própria instituição, parecem não mais assegurar compensações à altura de tamanho investimento.

O denominado individualismo, supostamente característico das sociedades pós-modernas, decorre, entre outras razões, da dificuldade, por parte de alguns grupos sociais, de continuar oferecendo remunerações simbólicas vantajosas ante as renúncias inerentes a qualquer pertencimento. Daí o "engajamento à la carte" e a sensação de "autorizamento" denunciados pelos pós-modernos.

Fragilidade institucional que corresponde à infidelidade previsível de seus agentes. Renuncia-se com mais facilidade. Redução do ônus de abrir mão.
Desencanar autorizado, estimulado, até. Transmutase do zen-budismo ao metro-sexualismo. Com os olhos bem abertos. Sem piscares nem passes de mágica. Apenas uma nova e real sociedade, condição material de uma nova socialização. O homem pósmoderno se faz andrógino.

Difícil de definir. Fonte de muitas expressões. Uma máquina de produzir impulsos. Com seus chips capitalistas. Tio Patinhas travestido de Boy George. Dessa forma, se o caráter plural, efêmero e incoerente desse novo homem é trazido à tona pelos teóricos do pós-modernismo, ${ }^{37}$ o mesmo ocorre com sua condição de consumidor. Existir e consumir aproximamse. Confundem-se, até. Para Baudrillard, ${ }^{38}$ certeza do cogito substituída pela do consumo. Condição de existência: consumo, logo existo. Para nós, também condição de identidade: dize-me o que consomes e te direi quem és.

Nas palavras de Zygmunt Bauman: “A sociedade pós-moderna envolve seus membros primariamente em sua condição de consumidores" ${ }^{39}$ Surge, assim, um novo tipo de consumidor. Aquele - idealizado pelos grupos de referência - há muito deixou de existir. Conclusões explicativas do consumo a partir da posição social do consumidor "tornaramse capengas". ${ }^{40}$

As grandes categorias mostraram-se inadequadas. A identidade do novo consumidor é, agora, negociada nas complexas interações sociais em que está envolvido. Multiplicaram-se as fachadas. ${ }^{41} \mathrm{Num}$ comércio incessante de representações, no qual a mesma pessoa representa várias demandas, sem qualquer uniformidade ou padrão de consumo. Muitos consumidores num só homem.

Homem que, além de múltiplo, é mutável. ${ }^{42}$ Máscaras em profusão, sobrepostas com agilidade. Para necessidades sociais nunca tão explicitamente inéditas. ${ }^{43}$ Máscaras que objetivam novas personagens. Para si e para os outros. Personagens que revelam um ator versátil. Que abrigam em seu interior infinitas imagens sociais. Passageiras. Efêmeras. Fragmentos que não tardam em se desfazer. Esse é consumidor em tempos pós-modernos: dilacerado e perecível. Segundo Zygmunt Bauman,

a multidão urbana não é uma coleção de indivíduos. É mais um agregado indiscriminado e sem forma em que se dissolve a individualidade. A multidão é sem rosto, mas também o são suas unidades. ${ }^{44}$

Agora, em lugar de uma identidade estável, coerente e única, o consumidor assume outra, plural, mutável, incoerente. Diretamente relacionada a um espaço específico ${ }^{45}$ e a uma determinada situação social. Negociada numa interação intersubjetiva marcada mais por singularidades que por generalizações. ${ }^{46}$ É um experimentador. Um improvisa- 
dor. Um mutante. Um sujeito blip por natureza. Por natureza socializada. Feito de cacos de experiências e algumas informações. Que pode ser isso e aquilo ao mesmo tempo. Numa lógica fundada no $e$ em detrimento da do ou.

As interações sociais na pós-modernidade não requerem uma única referência identitária. ${ }^{47}$ Apresentamo-nos com menos precisão. Menos definitivamente. Assim se nos é exigido. Tampouco cernimos em detalhe nossos interlocutores. Por isso, parecem mais facilmente substituíveis. Daí o descompromisso autorizado. Estar no lugar de ser. Ética do ficar.

Com quantos apetecer. Poucos ou muitos. Ou mesmo nenhum. Em nome dos afetos. Que só se fazem substituir. Pluralidades em relação. Imprecisão de expectativas. Indeterminação do ser e das representações que dele se constrói. Antes, na pré-pós, exigiase uma certa apresentação de si repetida, que se mantivesse ante qualquer nova condição objetiva de existência.

Hoje, no entanto, na pós-pré, o que habitualmente oferecemos ao mundo social como definidor de nós mesmos não é mais esse hipotético substrato que nos representava, mas algo muito mais complexo. Que reflete essa circulação da multiplicidade da diferença estabelecida na sociedade contemporânea. ${ }^{48}$ Estilhaçamento do $\mathrm{eu}$.

$E u$ que nunca foi tão descontínuo e indeterminado. Prevalecendo, como nunca, "a sensação do efêmero".49 Tornar-se diferente de si mesmo - isto é, um outro a todo instante - é a realidade desse novo homem. ${ }^{50}$ Homem sem R.G. ontológico, dessubstanciado, ator de múltiplas personagens. Frustrado por saber que nunca sairá do palco. ${ }^{51}$ Sobre isso Kaufman sentencia: "A identidade é justamente o resultado deste esforço infrutífero, mas incessante do indivíduo para fabricar sua unidade" ${ }^{52}$

Nem a desesperada tentativa de se criar targets particulares é mais possível. O indivíduo não serve mais, nem como grupo de referência de si mesmo. Perdeu seu centro, sua unidade. Converteu-se numa "verdadeira metamorfose ambulante", nas palavras do cantor e do mago. ${ }^{53}$ Assim é o consumidor pós-moderno. Como, então, fisgá-lo? Seria o fim do marketing?

\section{Meeting Points: a emergência de um novo paradigma}

Como é da natureza do desenvolvimento científico, um novo paradigma não tardou. ${ }^{54}$ Mas, agora, com uma diferença fundamental em relação ao anterior: a ilusão daquele consumidor idealizado já não mais existe. O marketing voltou-se, com isso, para áreas socioculturais que dizem respeito ao mercado: como os meeting points. Assim, para entendermos melhor como operam essas áreas, dividimos essa parte em duas outras sub-partes: da cultura real à cultura possível e dos produtos às marcas.

\section{a. Da cultura real à cultura possível}

Os meeting points são, no olhar de Egeria di Nallo, como as praças italianas: espaços que concentram um estilo de consumo determinado e onde circulam variados fluxos comunicacionais. Neles, os consumidores, sempre em trânsito, entram e saem, afetando e sendo afetados. Neles, um produto pode se encontrar em múltiplas posições. Um mesmo carro pode ser encontrado no "estilo de consumo esportivo" ou no "estilo de consumo de luxo", podendo, portanto, transitar entre essas áreas.

Os meeting points são, assim, caracterizados por um código de duas faces: o de mercado (lucrativo/ não lucrativo) e o específico (a título de exemplo: esportivo/ não esportivo), que expressa sua cultura particular num determinado momento - a cultura real. O código específico tem seus conteúdos constantemente modificados pelos diversos "filões comunicacionais" como o jurídico, o político, o tecnológico, o ecológico, etc. Assim, o movimento ecologista, lutando pelos animais e suas peles, transformou, na década de 70, o estilo de consumo do luxo.

Nesse caso, se, por um lado, houve mudança nos tecidos utilizados para a fabricação dos produtos de luxo; por outro, os códigos binários lucrativo/não lucrativo e luxuoso/não luxuoso se mantiveram. Ainda: o salto alto pode estar em voga, mas se certo tipo de tênis esportivo assimilar essa tendência, fatalmente será excluído do meeting point esportivo. A essas mudanças potenciais, a futura cultura real, denomina cultura possível.

Essa lógica interna de auto-preservação dos meeting points se aproxima do conatus espinosano. “Toda coisa, na medida em que pode, esforça-se por preservar no seu ser".55 Somos parte da Natureza. E como em seu interior não há nada que tenha em si algo pelo qual possa ser destruído - afinal tudo o que é afirma e não nega a sua essência - somos orientados por um movimento natural de insistência na própria existência. Existir é insistir.

Nada fazemos sem afirmarmo-nos no mundo. Tudo o que há, todo o ser, esforça-se, na medida em que pode, para continuar a ser. Todos os seres são dotados necessariamente de uma força interna de auto-preservação. Nada escapa a essa verdade. Eis o conatus espinosano. Eis nossa essência atual.

Essa mesma inclinação de auto-preservação dos meeting points está presente nos campos sociais conceituados por Pierre Bourdieu. Nesses, as disputas garantem a sobrevivência do espaço, a reprodução do jogo que nele se objetiva e as concordâncias implícitas que o tornam possível.

Um campo é um espaço abstrato. Não corresponde a um lugar geográfico. Espaço de posições sociais. Cujo sentido e valor só se definem umas em relação às outras. Espaço dinâmico de posições. Seus ocupantes se relacionam, afetam-se, redefinindo-as ininterruptamente. Espaço estruturado de posições. Seu 
funcionamento independe de quem as ocupa. Sua lógica é soberana face à singularidade dos agentes de plantão.

Um campo é sempre relativamente autônomo. Porque nunca completamente. Autonomia relativa que se objetiva em troféus. Objeto de uma luta que discrimina seus agentes. Cujo valor só é por eles reconhecido. Autonomia de valores e de sentidos. Com códigos específicos que permitem atribuir um significado também específico às coisas. Às coisas consumidas. Como nos meeting points.

Autonomia também normativa: regras cuja legitimidade e aplicabilidade se restringem ao espaço. Às relações que o constituem. Heresia controlada em zonas de subversão autorizada. Limites protetores de sua soberania, da continuidade do jogo.

Por fim, autonomia de capital. Sempre atribuído porque reconhecido - pelos demais agentes. Condição da posição ocupada. Da autoridade exercida. Resultado das posições já ocupadas. Das relações mantidas. Da trajetória percorrida. Da história no campo. Capital específico, válido para o jogo em disputa e com altas taxas de conversão para outros espaços. Transferência dissuadida pelo custo de saída e de entrada. Inércia do social. Ordem do social.

É, assim, por meio da identificação dos filões comunicacionais e da análise de seus respectivos pesos nos campos sociais de Bourdieu e nos meeting points de di Nallo, que o marketing passa agora a interpretar e a intervir no mercado. Projetam-se cenários futuros (culturas possíveis) a partir dos trends (tendências) estabelecendo cotas de mercado adequadas e posicionando corretamente a empresa.

Uma evidente conseqüência desse novo paradigma é a mudança do foco do produto às marcas. Se antes as organizações pesquisavam o desejado por um nicho de consumidores, empenhavam-se em criar ofertas que atendessem às exigências identificadas em suas pesquisas; agora, o que cobiçam é a criação de signos deslocados do próprio produto. Signos esses que venham permitir a circulação de sua mercadoria pelos diversos meeting points, seguindo, adequadamente, sem desvios, os trends. Esse novo fenômeno e suas conseqüências sociais é o que nos entreterá na seqüência.

\section{b. Do produto às marcas}

Nesse novo paradigma, preocupamo-nos até aqui com o marketing em seu funcionamento. Resta-nos apreendê-lo enquanto fenômeno social. Observá-lo de fora, como uma coisa, na condição de fato social. Outra não seria a orientação metodológica de Durkheim, e de suas Regras.

O flagrante científico, propriamente sociológico, da atividade mercadológica denuncia uma metamorfose. Transformação de uma coisa, ou da representação dessa coisa, inscrita em algum mercado, operada por um corpo de agentes socialmente auto- rizados para tal. Transformação em fetiche. Fetiche da mercadoria. Um dos mais nefastos efeitos da ideologia. Ao menos para Marx e seus herdeiros.

Para esses, no modo de produção capitalista os homens se alienaram do seu próprio trabalho. Graças à divisão social das atividades laborais, alguns poucos passaram a dispor de meios para explorar o trabalho de outros - apropriando-se, com isso, do produto dele resultante, antes mesmo de realizado. Esses outros, uma vez expropriados, não mais se reconhecem como causa da própria produção, como criadores de suas criações.

O trabalho, outrora tido como o atributo singularizador do caráter criativo humano, converte-se em instrumento de escravidão. Algoz de seu próprio agente. Já os homens, outrora senhores desse trabalho, passaram a perceber sua obra com certo estranhamento. Aos seus olhos, o resultado de sua produção autonomizou-se. Passou a parecer-lhes independente de suas deliberações, de seus métodos, procedimentos, condutas e estratégias.

Com isso, as mercadorias produzidas ganharam status de fetiche. Passaram a ser vistas como alguma coisa que existe em si e por si, como substâncias. ${ }^{56}$ Retirada a qualidade modal ${ }^{57}$ da mercadoria, essa passou a ter vida própria, a agir sobre os próprios homens - de forma a subjugá-los. O mundo, então, nas palavras de Chaui, "transformou-se numa imensa fantasmagoria." 58

Assim, por meio do dinheiro, equivalente social geral para todas as outras mercadorias, é dado início a um processo particular de relação entre as mesmas. Essas passam a se relacionar de forma fantástica, como se fossem sujeitos sociais. Uma calça jeans ( $R \$ 150,00)$ se relaciona com um relógio ( $R$ \$ $300,00)$ e com tantas outras mercadorias. Mas não só.

Essas relações deixam de ser percebidas como operações humanas. ${ }^{59}$ Tornam-se relações entre objetos, tomados agora como animados: a calça jeans perde, em grande medida, sua função de uso inicial - perspectiva utilitarista. Deixa de ser um objeto para nos vestir; para representar, então, um modo de vida jovem e feliz. Passa abrigar em seu tecido a mais alta das aspirações humanas, a liberdade. Liberdade para vestir "uma calça velha, azul e desbotada, que você pode usar do jeito que quiser, não usa quem não quer".60 Liberdade da calça que corresponde a meio relógio, isto é, meio viver luxuoso. Um luxo para duas liberdades. Que aqui se relacionam através do relógio e do jeans.

A mercadoria quando fetichezada passa, assim como Deus, ${ }^{61}$ a atuar como um saciador do que nos está ausente..$^{62}$ Deus é o nome que damos àquilo que supre todas as nossas faltas. Que corresponde a todas nossas esperanças. Pelo menos se tomado no seu sentido judaico, cristão ou islâmico - isto é, uma entidade transcendental, suprasensível, onipotente e onipresente. É o universal saciador do que nos 
está ausente. É o encontro do logos com Eros. ${ }^{63}$ É a comida do faminto, o ansiolítico do depressivo, o pé da pegada, a estrela da luz... Ou melhor: o fim do desejo por comida do faminto, o fim do desejo por ansiolítico do depressivo, o fim de todos os nossos tormentos. De todas as ausências. Das agressões do real. É o nome que damos a isso tudo.

Por isso Deus é ausência pura. Está totalmente fora do mundo. Porque é justamente o que lhe falta. É o sentido absoluto. Um mundo por detrás do próprio mundo. Um novo mundo. Tomado como verdadeiro. O verdadeiramente verdadeiro. Tudo remete a ele. É desse modo que o real perde seu título ontológico. E ganha status de signo. O verdadeiro sentido está cifrado. Tudo é sinal. Pansemiologismo.

Olhamos para um jeans na estante e vemos um signo. Um signo que como todo signo nos remete a um sentido. Sentido que, como bem observou Wittgenstein, só pode estar fora do mundo. Melhor: fora da própria coisa. Fora do próprio significante. No sujeito que significa. Pois só ele deseja. Caso contrário, onde estaria o sentido das coisas? Nelas mesmas? Se a resposta for afirmativa, cabe uma segunda pergunta: em todos os seus átomos?

Mas o sentido é, pelo menos para o materialismo, o por detrás das coisas, o para além delas. A tradução de nossa insatisfação com o mundo. É porque o mundo não nos satisfaz plenamente, é porque ele também agride, que significamos. $\mathrm{O}$ mundo não basta. Somos impotentes diante de suas infinitas forças. Assim, temos de construir um outro mundo. Seguro. Que não agrida a nossa existência. Um mundo para além da própria realidade. Imaginário. Que lhe dê sentido. O sentido da vida só não está na própria vida. Em especial quando ela é triste.

Mas voltemos às mercadorias. Já dissemos que elas, quando fetichezadas, saciam o que nos está ausente. Mas não qualquer ausência. Graças à propaganda, elas nos remetem a uma falta específica: um jeans não significa qualquer coisa. Significa um desejo particular, um desejo nosso por liberdade. Todo objeto físico, quando significado, refrata a realidade, mas sempre de forma mais ou menos determinada ${ }^{64}$ Uma pegada de um pato na areia não nos conduz a um copo de cerveja. Tampouco de vodka. Tristeza do alcoólatra, que caminha solitário. Alude ao animal, aos patos em quadrinhos, ou talvez a um equipamento de mergulho. $\mathrm{O}$ jeans, antes panos e costuras, é agora, no modo de produção capitalista, a própria liberdade materializada. Liberdade essa criada nas agências de propaganda. Objetivada nos anúncios. Vendida nas lojas. ${ }^{65}$ Onde corpos escravizados carentes de sensações libertadoras se convertem em meros consumidores.

É dessa forma que os anúncios passam a vender sentidos e não mais simplesmente produtos. Aliados a outros instrumentos do marketing, tais como os pontos de vendas, o merchandising, as embalagens, os rótulos, os logotipos da organização ou produto etc., enfeitiçam o consumidor convertendo o produto em mero habitar, em mera objetivação, de uma entidade própria, com um sentido particular denominada marca. ${ }^{66}$

A marca é "uma entidade perceptiva". Enquanto "conexão simbólica entre uma organização, sua oferta e o mundo do consumo" ${ }^{67}$ é, muitas vezes, o próprio objeto de troca, o objeto comprado pelo consumidor. O que se adquire num shopping, num supermercado, numa loja não é, nesses casos, um produto com uma função específica - desempenhar esse ou aquele papel na produção -, mas carregado de significado, convertido em signo. ${ }^{68}$

A marca autoriza, portanto, criar um valor a mais para o produto dando-lhe sentido único, transformando-o em signo. Perde, com isso, sua função original de identificação. Passa a situar-se num plano distinto, de significação própria. Sua autonomia, destarte, pode chegar a ser tal, que "adquire um sentido totalmente descolado do objeto". ${ }^{69}$ É por isso, portanto, que uma mesma marca pode estar presente nos mais diversos produtos. Uma marca de caneta - como a Mont Blanc, conta com uma linha de cintos, relógios, perfumes. Afinal, ela não identifica apenas uma linha de canetas, mas representa também um tipo especial de desejo, enquanto signo de sofisticação.

Para Baudrillard, a marca pode comportar uma série de signos. Constituir um "supersigno".70 A mesma Mont Blanc que significa sofisticação, também significa riqueza, poder, sucesso etc. Simulacro, portanto. Essência da pós-modernidade. Compra-se a marca e não o produto. Prefere-se a imagem ao objeto. A cópia ao real. Porque o simulacro não é pura representação, embeleza o próprio real, o faz mais brilhante, mais próximo daquilo que desejamos como real. O hambúrguer sem graça dá água na boca na fotografia. A calça jeans se destaca na topografia discreta da modelo.

E, cada vez mais, insaciável torna-se o novo consumidor. Desejante de seu próprio delírio. Ávido por suas próprias ilusões. Preso aos seus próprios fantasmas. Acorrentado às imagens que cria. Fascinado pelo que não é - a não ser para si mesmo. Convertendo toda mercadoria em seu espelho. Narciso vai às compras.

Essa insaciabilidade é o traço mais característico do consumidor atual. ${ }^{71}$ Porque "o homem contemporâneo tem uma fome de mais e mais bens", ${ }^{72}$ acaba se dando conta de uma "tensão econômica", ${ }^{73}$ isto é, de que todas essas necessidades e desejos jamais serão satisfeitos. Afinal, desde $O$ Banquete, "quando uma necessidade é preenchida, diversas outras habitualmente aparecem, para lhe tomar o lugar". ${ }^{74}$

Frente a tanta insatisfação, o marketing cons- 
trói à sua maneira um real espetacular, que nos encanta. Um hiper-real. Esse outro mundo fascinante é o que consumimos. Mundo que cada vez mais é super-recriado pelos signos, e cada vez menos revela as condições materiais que o determinam. Desreferencialização do real.

Um produto para circular entre vários meeting points, para convergir com os trends, não mais pode ser um mero instrumento de produção, mas tem de se transformar em signo. Em vários signos. Um carro não tem apenas uma função, mas ao entrar no "estilo de consumo de luxo" é signo de sofisticação, ao entrar no "estilo de consumo esportivo" é signo de jovialidade e assim por diante. Para que esse processo de produção simbólica se efetue, a publicidade tem, portanto, não mais de anunciar produtos, mas sim, de significar marcas. Não é por menos que as pesquisas qualitativas - muito utilizadas na era do target - começam a ceder espaço para a abordagem semiótica, que, a partir da análise do próprio produto, infere os efeitos potencialmente gerados por ele, analisando-se a intenção da organização e se ela vai ou não ao encontro das culturas possíveis. Enfim, se os signos da marca são adequados.

Desta forma, concluímos que se, por um lado, a mudança paradigmática do marketing abordada nesse texto sofisticou o próprio marketing; por outro, ao dar vida própria às marcas, contribuiu para que as relações sociais por detrás das mercadorias fossem ainda mais mascaradas. Por isso, podemos dizer que os tempos pós-modernos de forma alguma eliminaram a ideologia, ${ }^{75}$ mas, pelo contrário, intensificaram-na. Tornaram seu processo mais complexo.

Se até agora ideologia era aproximada à idéia de identidade entre desiguais, ${ }^{76}$ agora a ideologia é fundada na diferença. Lembremos de que, como bem observou Terry Eagleton no seu clássico "Ideologia", nem toda ideologia elimina realmente a diferença, nem toda ideologia está fundada na igualdade. "Aceito as pessoas como elas são." "O mundo precisa de todo tipo de gente." "Ainda bem que nem todo mundo pensa igual." São expressões consagradas pela sabedoria popular e que, muitas vezes, revelam-se como estereótipos, facilitadores culturais, simplificadores da realidade. Expressões com pretensões de verdades totalizantes. O casual day é um exemplo. Atividade que, por meio da suposta aceitação da diferença, acaba por contribuir para alienação dos agentes de uma empresa capitalista. Um entre muitos outros exemplos de como o processo ideológico tornou-se mais complexo na pósmodernidade. Quiçá, por isso, menos perceptível. Fim da crise para aqueles que com a revolução sempre sonharam. Começo da revolução para aqueles que para a crise nunca despertaram. E aqui os autores agradecem pelo sentido. Felizmente sempre atribuído pelo leitor. Responsabilidade transferida. mFAmEcos

\section{NOTAS}

1 Tais como a socióloga italiana Egeria di Nallo em seu clássico Meeting Points (di Nallo, E. Meeting Points, Cobra, São Paulo, 1999).

2 "Para ver a dificuldade que o profissional de marketing enfrenta, basta estar aqui, na linha de frente, no nosso departamento. É uma crise no dia a dia. No fazer mais corriqueiro." (Fernando Martins, diretor de marketing do Banco Real. Nosso entrevistado em 29/03/05).

3 “Considero 'paradigmas' as realizações científicas universalmente reconhecidas que, durante algum tempo, fornecem problemas e soluções modelares para uma comunidade de praticantes de uma ciência" (KUHN, T. A estrutura das revoluções científicas, São Paulo, Perspectiva, 2003, p.13).

4 "'Ciência normal' significa pesquisa firmemente baseada em uma ou mais realizações científicas passadas. Essas realizações são reconhecidas durante algum tempo por alguma comunidade científica específica como proporcionando os fundamentos para sua prática posterior" (Ibidem, p.29).

5 A tarefa de uma suposta ciência do marketing alguns denominam mercadologia - é aparentemente paradoxal: contra uma primeira tendência de considerá-la evidente, porque inscrita na ordem das coisas, e objetivada em previsíveis manuais, ela deve lembrar o caráter arbitrário, injustificável, e até mesmo, patológico das paixões, cujas manifestações constituem seu objeto. Para tanto, adota, com freqüência, como diria Bourdieu, uma retórica de distanciamento - denúncia da impossibilidade de objetivação do real pesquisado. Como exemplo, a pergunta sobre a anterioridade causal das mensagens publicitárias em relação aos desejos ou às necessidades apresentada, quase sempre, como alternativa "do que veio primeiro", contribui para fazer ignorar o caráter estruturante e estruturado, portanto interdependente, desses elementos em relação. Mas, por outro lado, essa ciência do marketing deve dar a tais manifestações uma razão de ser, uma necessidade explicada. Tirá-las do absurdo culpabilizado em que muitas vezes estão inscritas. Associá-las às suas paixões propulsoras, determinadas por uma illusio de pertencimento, de investimento em algum jogo social. Ilusão possível pelo ajuste, burilado em socialização, entre um espaço de jogo e tendências subjetivas de ação. Entre posições sociais iniciais e finais, ocupadas e desejadas, e disposições práticas em adaptação. Entre um campo e um habitus, em suma. 
6 Segundo Pierre Bourdieu, "o campo é um mundo social como os outros, mas que obedece a leis sociais específicas." Ou ainda: "A noção de campo está aí para designar esse espaço relativamente autônomo, esse microcosmo dotado de leis próprias." Para ele, "quanto mais autônomo for um campo, maior será o seu poder de refração e mais as imposições externas serão transfiguradas, a ponto, freqüentemente, de se tornarem perfeitamente irreconhecíveis. O grau de autonomia de um campo tem por indicador principal seu poder de refração, de retradução. Inversamente, a heteronomia de um campo manifesta-se, essencialmente, pelo fato de que os problemas exteriores, em especial os problemas políticos, aí se exprimem diretamente". BOURDIEU, P. Os usos sociais da ciência, São Paulo, UNESP, 2003, pp. 20-22.

7 Nessa perspectiva de conflito e deslegitimação, Theodore Levitt sentencia: "Os professores também entendem alguma coisa de pomposidade, especialmente na linha da ofuscação literária mascarada como sabedoria". (LEVITT, Th., A imaginação de marketing, São Paulo, Atlas, 1986. p. 20).

8 Segundo Pierre Bourdieu, "o capital científico é uma espécie particular de capital simbólico (o qual, sabe-se, é sempre fundado sobre atos de conhecimento e reconhecimento) que consiste no reconhecimento (ou no crédito) atribuído pelo conjunto de pares-concorrentes no interior do campo científico" (Ibidem, p.26).

9 Abordagem assinada por Egeria di Nallo. Socióloga italiana. De Bolonha. Aponta para o nascimento de uma nova tradição. Denuncia uma revolução: a que vive o marketing hoje.

10 Target significa, literalmente, alvo. No jargão mercadológico é usado como "público-alvo".

11 Documento destinado a "todos aqueles que, eventualmente, necessitam de maiores detalhes sobre a conta (do anunciante)" FERRARI, F. Planejamento e atendimento. A arte do guerreiro, São Paulo, Loyola, 1997, p. 64.

12 Já McCarthy, em seu notável Basic Marketing, inquietava-se com a pergunta que se impunha: "Who, in fact, is the consumer? How does he act in the market place?" (McCARTHY, J. Basic Marketing, Homewood, Richard Irwin, 1960. p. 36)

13 "Hoje, a maioria das empresas está abandonando o marketing de massa. No seu lugar, estão praticando a segmentação e o targeting, identificando segmentos de mercado, selecionando um ou mais de um dentre eles e desenvolvendo pro- dutos para cada um deles". ARMSTRONG, G. \& KOTLER, Ph., Marketing - an introduction, New Jersey, Prentice Hall, 2000, p. 179.

14 CHAUI, M. Público, Privado, Despotismo, IN: Ética, org. Adauto Novaes, São Paulo, Cia das Letras, 2000, p.346.

15 Intensificada no início dos anos 30 com o fordismo, padrão de produção no qual a organização desde a produção da matéria prima até a distribuição comercial de sua oferta.

16 Tal segmentação na doutrina do marketing remota ao clássico Modern marketing, cujos autores BARKER \& ANSHEN - já em 1939 - sentenciavam: “Variações nos hábitos de compra podem ser causadas por diferenças de sexo, idade, renda, lugar de residência, tamanho da família, ocupação do arrimo, background racial, e outros fatores". (BARKER, C. W. \& ANSHEN M. Modern Marketing, New York, McGraw-Hill, 1939. p. 22.

17 BOURDIEU, P. La distinction, Paris, Minuit, 1979, p.136. Como veremos adiante, para os teóricos da pós modernidade, tornou-se impertinente classificar o social a partir de grupos de referência. Mais ainda: seu enraizamento geográfico, relativizado: as distâncias foram encurtadas pelas novas tecnologias, dispensando-nos grandes e custosos deslocamentos. Assim, visitas virtuais a museus, videoconferências, dvds no lugar de cinema, múltiplos procedimentos para educação à distância são exemplos reveladores. Com isso, a questão geográfica deixaria de ser relevante para a determinação de um certo estilo de vida, de um certo padrão de consumo. É forçoso lembrar, no entanto, que o recurso a esses facilitadores tecnológicos não é indiscriminado. Os recortes obsoletos da sociologia moderna denunciam os capitais econômico e cultural/escolar como variáveis desse uso. O knowledge gap, apontado por Tichenor, nos faz lembrar que o intervalo de conhecimento entre receptores bem-preparados e mal-preparados só aumenta com a informação midiatizada. Questiona, portanto, a premissa de que distribuição de bens culturais num espaço geográfico socialmente hierarquizado se democratizaria na pós-modenidade, com o desenvolvimento tecnológico dos meios de comunicação. Sobre a teoria do knowledge gap, ler BARROS FILHO, C. Ética na Comunicação, São Paulo, Summus, 2003, pp. 222-227.

18 Segundo Sébastien Charles, essa proposta é insatisfatória para explicar o consumo: "O problema das teorias da distinção, como a de Bourdieu, é que elas não explicam por que as lutas de competição de prestígio entre grupos sociais do- 
minantes, tão antigas como as primeiras sociedades humanas, puderam estar na origem de um processo absolutamente moderno, sem nenhum precedente histórico; nem como puderam surgir na ordem da aparência o motor da inovação permanente e a autonomia pessoal. Portanto as rivalidades de classe não podem ser o princípio explicativo das variações incessantes da moda". (SÉBASTIEN, Ch. O individualismo paradoxal: introdução ao pensamento de Gilles Lipovetsky, In: Os tempos hipermodernos, Gilles Lipovetsky, São Paulo, Barcarola, p.17).

19 “É essa transformação do saber incorporado em automatismos e em intuições que permitem a improvisação no comportamento e uma invenção relativa de variantes em função das variantes da situação." (ACCARDO, A. Introduction à une sociologie critique, Bordeaux, Le Mascaret, 1997, p.121).

20 "A meu ver, o mercado de massas está definitivamente morto e já ingressamos na era da personalização em massa. As estratégias devem ser desenvolvidas para cada nicho identificado e devemos estar atentos às novas oportunidades depersonalização. A informática e os recursos da automação em fábricas, hoje, permitem a produção de versões individualizadas de produtos a um preço acessível e esse é o sonho de todo consumidor." (KOTLER, Ph. Personalização em massa, In HSM Management, N. 5, Nov/1997, p. 140.)

21 Michel Maffesoli, respondendo a pergunta sobre o início da pós-modernidade em palestra ministrada na Faculdade Cásper Líbero em 2004. E para além das panelas, as donas de casa. Lipovetsky, em fina análise, complementa: "No mundo do hiperconsumo, até a dona-de-casa pode ser reciclada..." (LIPOVETSKY, G. Os tempos hipermodernos, São Paulo, Barcarolla, 2004, p. 34.

22 Segundo Terry Eagleton, “A palavra pós-modernismo refere-se em geral a uma forma de cultura contemporânea, enquanto pós-modernidade alude a um período histórico definido." Mas, assim como ele, embora reconheçamos a utilidade dessa distinção, não a faremos. Abordaremos ambas como idênticas Como "uma linha de pensamento que questiona as noções clássicas de verdade, razão, identidade e objetividade, a idéia de progresso ou emancipação universal, os sistemas únicos, as grandes narrativas ou os fundamentos definitivos de explicação. Contrariando essas normas do iluminismo, vê o mundo como contigente, gratuito, diverso, instável, imprevisível, um conjunto de culturas ou interpretações desunificadas gerando um certo grau de ceticismo em relação à objetividade da verdade, da história e das normas, em relação às idiossincrasias e a coerência de identidades." (EAGLETON, T. As ilusões do pós-modernismo, Rio de Janeiro, Zahar, 1998, p.7).

23 Ainda que, para alguns autores, trata-se, na verdade, não de um período de ruptura radical com o anterior, mas apenas de um período de redefinição de caminhos. Sobre essa perspectiva, ler: LYOTARD, J-F. La Condition Post-Moderne, Paris, Minuit, 1979.

24 Definição apresentada em palestra ministrada por Michel Maffesoli para o núcleo de pesquisa em Comunicação e Práticas de Consumo da Escola Superior de Propaganda e Marketing em 26/04/05.

25 Idem.

26 "Não basta apenas inventar simplesmente novos termos, como pós-modernidade e outros. Em lugar disso, temos de olhar para a própria natureza da modernidade, que, por motivos justamente específicos, tem sido até agora apreendida de maneira pobre pelas ciências sociais. Em vez de penetrarmos num período de pós-modernidade, vamos na direção de um período no qual as conseqüências da modernidade se tornam mais radicalizadas e universalizadas do que antes. Afirmo que, para além da modernidade, poderemos perceber os contornos de uma nova e diversa ordem, que é a "Pós-moderna"; mas que isso é completamente distinto do que no momento presente está sendo chamado por muitos de "pósmodernidade" (GIDDENS, A. The consequences of modernity, Palo Alto, Stanford University Press, 1990, p. 3).

27 Lyotard reinventa um dos mais antigos modelos da temporalidade, ou seja, o tempo cíclico, o único que poderia autorizar a posição convenientemente ultrajante que o pós-modernismo não segue, mas que antes precede o verdadeiro modernismo em si, cujo retorno ele prepara (LYOTARD, J-F. Réponse à la question, qu'est-ce que le postmoderne?, In Le postmoderne expliqué aux enfants Paris, Seuil, 1986, pp. 29 - 30. No mesmo sentido, Maffesoli também denuncia a anterioridade do pós-moderno em relação ao moderno na obra de Santo Agostinho. Sobre o tema ler MAFFESOLI, M. A parte do diabo, RJ, Record, 2003.

28 “...a dependência do pós-moderno ao que se mantém essencialmente como categorias do novo, que não podem ser totalmente erradicadas do "novo" sistema, seja qual for a sua retórica", (JAMENSON, F. Modernidade singular, Rio de Janeiro, Civilização brasileira, 2005, p. 13.

29 Dando seqüência à linhagem inaugurada por Epicuro e secundada por Lucrécio, sentenciamos: 
se a morte é não ser, já a vencemos uma vez: no dia em que - triunfalmente - nascemos. Triunfo de Aníbal! Filho suicida de Amilcar e amante de elefantes. Cartaginês.

30 Termo empregado pela primeira vez em 1947 pelo historiador Toynbee. E que ganha força nos libertadores anos sessenta.

31 CHAUI, M. op. cit., p.346.

32 Como observa Mongardini, "se a representação de classe acompanhou o processo de racionalização, de publicidade, de definição de correlações econômicas no espaço social, hoje fenômenos religiosos, étnicos, raciais, e os valores do localismo rompem a generalização do modelo economicista e criam uma configuração absolutamente diferente desse espaço, dentro do qual grupos exclusivos, seitas, sociedades secretas, movimentos religiosos e étnicos, nacionalismos e interesses transversais abrem o caminho para a representação de uma sociedade sem classes. No sentido de que a classe tornou-se um elemento marginal na estrutura do espaço social, na construção da identidade do sujeito". MONGARDINI, C. Spazio sociale e cultura moderna, In Teoria sociológica stratificazione sociale. Roma, Nis, 1986, p. 60.

33 di NALLO, E. op. cit. p. 150.

34 Sobre essa perspectiva deleuziana, ler Mil Platôs e $\mathrm{O}$ antiédipo, ambos traduzidos pela editora 34 .

35 Segundo Jair Ferreira dos Santos, o homem pós-moderno é, de certa forma, elogiado por alguns teóricos e abominados por outros: para Lipovetsky, Fiedler e Toffler ele é como uma "criança radiosa - um indivíduo desenvolto, sedutor, hedonista integrado à tecnologia, narcisista, com identidade móvel, flutuante e liberado sexualmente". Já para Nietzsche, Baudrilllard e Lyotard ele é como um "andróide melancólico um consumidor programado e sem história, indiferente, átomo estatístico na massa, boneco da tecnociência". (SANTOS, J. op. cit. p., 11)

36 "Até há pouco a massa moderna era industrial, proletária, com idéia e padrões rígidos. Procurava dar um sentido à História e lutava em bloco por melhores condições de vida e pelo poder político. Crente no futuro, mobilizava-se para grandes metas através de sindicatos e partidos ou apelos nacionais. Sua participação era profunda (basta lembrar as duas guerras mundiais). A massa pós-moderna, no entanto, é consumista, classe média, flexível nas idéias e costumes. Vive no conformismo em nações ideais a acha-se seduzida e atomizada (fragmentada) pelos mass media, querendo o espetáculo com bens e serviços no lugar do poder. Participa, sem envolvimento profundo, de pequenas causas inseridas no cotidiano - associações de bairro, defesa do consumidor, minorias raciais e sexuais, ecologia". (SANTOS, J. op. cit., pp. 89 - 90)

37 Zygmunt Bauman denuncia os problemas éticos que essa nova concepção de homem pode vir a resultar. Em "Amor líquido" critica a proposta da americana Caryl Rusbult da Universidade da Carolina do Norte de comparar um relacionamento a um investimento como outro qualquer. Investe-se numa relação como no mercado de capitais. Ambos são extremamente voláteis. Assim são as ações, assim são as pessoas. Por isso, para Adrienne Burges, "as promessas de compromissos a longo prazos são irrelevantes". Afinal, nenhum investidor com um mínimo de sanidade juraria ser fiel para sempre a uma determinada ação. Numa relação amorosa deve-se, portanto, como na bolsa, comprar quando os lucros parecem subir e vender quando parecem cair. Segundo Bauman, esse tipo de perspectiva só nos conduz a uma relação de incertezas, baseada num contrato que pode ser rompido a qualquer hora, até nas mais difíceis para um dos lados. (BAUMAN, Z. Amor líquido, Rio de Janeiro, Zahar, pp. 28-30).

38 BAUDRILLARD, J. La société de consommation. Paris.

39 BAUMAN, Z. Modernidade líquida, Rio de Janeiro, Zahar, 2000, p.90.

40 Mario René, profissional da área e nosso entrevistado em 18/02/2005.

41 “Será conveniente denominar de fachada a parte do desempenho do indivíduo que funciona regularmente de forma geral e fixa com o fim de definir a situação para os que observam a representação. Fachada, portanto, é o equipamento expressivo de tipo padronizado intencional ou inconsciente empregado pelo indivíduo durante sua representação." (GOFFMAN, E. A Representação do Eu na Vida Cotidiana, Petrópolis, Vozes, 2003, p. 29.

42 Nas palavras de Jair Ferreira dos Santos: “Na pós-modernidade, matéria e espírito se esfumam em imagens, em dígitos num fluxo acelerado." (SANTOS, J. op. cit., pp. 15-16).

43 Zygmunt Bauman destaca a sensação securitária que o celular nos proporciona nesses tempos de rápidas mudanças. "Estando com o seu celular, você nunca está fora ou longe. (...) Cada conexão 
pode ter vida curta, mas seu excesso é indestrutível. Em meio à eternidade dessa rede imperecível, você pode se sentir seguro diante da fragilidade irreparável de cada conexão singular e transitória. Dentro da rede, você pode sempre correr em busca de abrigo quando a multidão à sua volta ficar delirante demais para o seu gosto. Graças ao que se torna possível desde que seu celular esteja escondido com segurança no seu bolso (...)" (BAUMAN, Z. op. cit. pp 78 -7 9).

44 Idem, Ética pós-modena, São Paulo, Paulus, 1997, p. 178.

45 Zygmunt Bauman observa que "identidades só podem ser seguras e 'não problemáticas' dentro de um espaço social seguro: espaçamento e produção de identidade são duas facetas do mesmo processo" (BAUMAN, Z. Ética pós-moderna, São Paulo, Paulus, 1997, p. 266).

46 Segundo Michel Maffesoli, "que faz de mim um ser heterônomo", (MAFFESOLI, M. A Contemplação do Mundo, Porto Alegre, Ofícios, 1995, p. 78).

47 "As identidades parecem fixas e sólidas apenas quando vistas de relance, de fora. A eventual solidez que podem ter quando contempladas de dentro da própria experiência biográfica parece frágil, vulnerável e constantemente dilaceradas por forças que expõem sua fluidez e por contracorrentes que ameaçam fazê-la em pedaços e desmanchar qualquer forma que possa ter adquirido." (BAUMAN, Z. op. cit. , p.98).

48 Sobre isso, Michel Maffesoli destaca que "em uma tal perspectiva, a autonomia do sujeito, mestre e senhor de si mesmo, caiu em desuso. Também sua identidade forte fissura-se em várias partes." (op. cit., p.78)

49 CHAUI, M. op. cit., p. 347. A arte (ou melhor, a antiarte) contemporânea reflete bem essa sensação. A pop art, o minimal, o hiper-realismo, os happenings, as performances, o vídeo-arte, o grafite... enfim, seja qual for o estilo, ele trabalha com o momento, com o passageiro, nunca com o eterno - pretensão típica dos artistas anteriores a esse período.

50 Sobre os traços característicos da vida privada desse novo homem, Chaui escreveu: "Quatro traços parecem marcar a esfera privada pós-moderna: a insegurança que leva aplicar recursos no mercado de futuros e de seguros; a dispersão, que leva a procurar uma autoridade política forte, com perfil despótico; o medo, que leva ao reforço de antigas instituições, sobretudo a família e a pequena comunidade da "minha rua" e o retorno a formas místicas e autoritárias da religiosidade; o sentimento do efêmero e a destruição da memória objetiva dos espaços, que levam ao reforço dos suportes objetivos da memória (diários, fotografias, objetos), fazendo, como disse um autor, com que a casa se torne uma espécie de pequeno museu privado." (Ibidem, pp.387-388).

51 Goffman já observava: “O mundo todo não constitui evidentemente um palco, mas não é fácil especificar os aspectos essenciais em que não é." (GOFFMAN, E. op. cit. p. 29).

52 KAUFMANN, J-C. Ego. Paris, Nathan, 2001. p. 262.

53 SEIXAS, R. \& COELHO, P. Metamorfose Ambulante, In Raul Vivo, São Paulo, Eldorado, 1983.

54 É importante atentar para o fato de que uma mudança de paradigma implica uma nova forma (gestalt) de perceber um determinado fenômeno (no caso o marketing) e não uma apenas uma nova forma de interpretá-lo, afinal, toda interpretação já pressupõe uma base de conceitos preestabelecidos, isto é, já pressupõe um paradigma. Segundo Thomas Kuhn, "em períodos de revolução, quando a tradição científica normal muda, a percepção que o cientista tem de seu meio ambiente deve ser reeducada - deve apreender a ver uma nova forma (gestalt) em algumas situações com as quais já está familiarizado. Depois de fazê-lo, o mundo de suas pesquisas parecerá, aqui e ali, incomensurável com o que habitava anteriormente." (KUHN, T. op. cit. p. 148).

55 ESPINOSA, B. Ética à maneira dos geômetras, São Paulo, Atena, s/d, Parte III, prop. VI, p. 147.

56 “Entendo por substância o que é em si e se concebe por si: isto é, aquilo cujo conceito não tem necessidade do conceito de outra coisa, do qual deva ser formado." ESPINOSA, B. op. cit. Definição I, Parte I, pg. 15.

57 "Entendo por modo as afeç̧ões (affectiones) da substância, ou por outra, o que existe em outra coisa, mediante a qual também é concebido." Ibidem, Definição V, Parte I, pg 15.

58 CHAUI, M. O que é ideologia?, São Paulo, Brasiliense, 2003, p. 55.

59 Nesse momento ocorre um processo de inversão: as ações humanas é que passam operar em função das mercadorias. A título de exemplo, um vendedor é visto como mero meio para se obter uma mercadoria qualquer. 
60 Jingle publicitário da USTOP.

61 Pelo menos como o materialismo na sua forma mais pura o conceberia. A única diferença entre uma mercadoria qualquer e Deus é que esse último corresponderia a um saciador universal, enquanto, como veremos um pouco mais para a frente, a mercadoria corresponderia a um saciador particular.

62 Sobre a sacralização dos objetos de consumo nas sociedades capitalistas, Clotilde Perez destaca a dimensão das instituições mercantis - enquanto novos modelos arquitetônicos - em comparação às instituições religiosas - enquanto antigos modelos: "Nos velhos templos edificados a serviço de uma forma de religiosidade toda a atenção se canalizava no altar, ao passo que nos novos templos presentes em nossa sociedade de consumo a atenção se encontra por definição dispersa mediante uma profusão, sempre renovada e imprevisível, de marcas comerciais." (PEREZ, C. Signos da Marca, São Paulo, Thomson, 2004, p.113)

63 Sobre isso, ver Comte-Sponville, A. Traitè $d u$ désepoir de la beatitude. Tome 2, "Vivre", Paris, PUF, 1988. p. 228-234.

64 Bakhtin observa que "se converte em signo o objeto físico, o qual sem deixar de fazer parte da realidade material, passa a refletir e a refratar, numa certa medida, uma outra realidade". Marxismo e filosofia da linguagem. São Paulo, Hucitec, 2002. p. 31.

65 Sobre isso, Chaui observa: "A publicidade não opera para informar e promover um produto, mas criar desejos sem qualquer relação imediata com o produto (a imagem vende sexo, dinheiro e poder). A própria imagem precisa ser vendida, donde a competição enlouquecida das agências de publicidade que sabem que uma imagem é efêmera e que seu poder de manipulação é muito limitado no tempo, sendo imprescindível seu descarte e troca veloz". CHAUI, M. op. cit., p. 386.

66 Nesse ponto, é surpreendente como muitos teóricos do marketing - como Drucker e Kotler em sua extensa obra-equivocam-se ao abordá-lo como uma disciplina voltada à satisfação de uma demanda. É evidente, e nesse ponto eles estão corretos, que o marketing lida com mercados, com sistemas de trocas. Contudo isso não implica que sua função seja identificar e corresponder às vontades dos consumidores. Convergir seus interesses com os dos produtores. Como se houvesse uma demanda potencial de desejos insatisfeitos naturais ao homem que servisse como guia para a criação de produtos que viessem a satisfazê-la. Muito pelo contrário. O marketing visa criar novas demandas para, então, satisfazêlas por meio de uma oferta antes inexistente. Isto é, faz crer aos consumidores que seus interesses são idênticos aos produtos ofertados pelas organizações capitalistas. A finalidade do marketing, sob esse aspecto, nada mais é do que criar uma demanda de desejos específicos. Oferecer-lhes a possibilidade de sua satisfação, sempre, é claro, através de uma troca vantajosa para o capitalista. A origem dessa abordagem adotada pela doutrina oficial nos remete diretamente ao utilitarismo, que resumia o homem como um ser capaz de escolhas racionais. Assim, através do cálculo custo/benefício, ele seria capaz de optar pelo melhor para si. É óbvio - ainda mais depois do surgimento da psicanálise e do marxismo, que há muito já constataram que nossas ações são orquestradas, em grande medida, por forças cegas como o inconsciente e a ideologia. A posição desses teóricos deixa de ser surpreendente quando vemos o marketing como uma disciplina científica e acadêmica a serviço de interesses particulares: a reprodução da ideologia dominante e o lucro do capitalista. Longe de ter uma função esclarecedora, essa definição de marketing tem intenções morais: ao colocar o marketeiro como uma espécie de médico do desejo (diagnostica-o e o remedia) e não como um produtor de vontades, retira toda a carga moral desse profissional. Se o produto, sua distribuição, seu preço e sua promoção são imorais, é porque a sociedade assim também o é. É ela, em última instância, a responsável por essa operação. Ao marketing cabe somente satisfazer a um Eros de origem externa a ele.

67 PEREZ, C. op. cit., p.10

68 Assim, para Semprini, a marca é um motor semiótico movido por nome, conceito, cores, sons, sonhos, e desejos. (SEMPRINI, A. Marche e mondi possibili. Un approccio semiotico al marketing della marca, Milano, Franco Angeli, 1993, p. 121.).

69 PEREZ, C. op. cit. , p.111.

70 Ver BAUDRILLARD, J. Para uma crítica da economia política do signo, Rio de Janeiro, Elfus, 1995.

71 Assim denuncia Campbell, C. em A ética romântica e o espírito do consumismo moderno. Rio de Janeiro, Rocco, 2001. p. 58.

72 FROMM, E. The Psychological Aspects of the Guaranteed Income, In The Guaranteed Income: Next Step in Economic Evolution?, org. Robert Theobald, Nova York, Doubleday, 1964 p. 179. 
73 O'NEILL, J. The Productive Body: An Essay on the Work of Consumption, In Queen's Quarterly, Nova York, 85, 1978, p. 225.

74 Jr. MARKIN, R. Consumer Behaviour: A Cognitive Orientation, Nova York, Macmillam, 1974, p. 195.

75 A pós-modernidade nega a noção de ideologia ao refutar duas de suas idéias centrais: a verdade - a de que o homem pode se livrar da falsa consciência - e a de que a sociedade é regida por uma luta de poderes entre, fundamentalmente, duas classes sociais antagônicas.

76 A identidade é, segundo Adorno, a forma primária da manifestação ideológica. Para ele a ideologia é "uma forma de 'pensamento da identidade', um estilo de racionalidade encobertamente paranóico, que transmuta de modo inexorável a unicidade e a pluralidade das coisas em um mero simulacro de si mesmo, ou as expulsa de suas fronteiras em um ato desesperado de exclusão" (EAGLETON, T. La ideología y sus vicisitudes en el marxismo occidental, In: Ideología Un mapa de la cuestión (org: Slavoj Zizek), Buenos Aires, Fondo de Cultura Económica de Argentina, 2003. p. 224. Assim, quando, por exemplo, o Estado burguês concebe a igualdade de todos os homens perante a lei, faz do proletariado a imagem e semelhança da burguesia, para que, assim, não veja sua condição de dominado. A ideologia, portanto, transformaria o heterogêneo em homogêneo.

\section{REFERÊNCIAS}

ACCARDO, A. Introduction à une sociologie critique. Bordeaux, Le Mascaret, 1997.

ARMSTRONG, G. \& KOTLER, Ph.. Marketing - an introduction. New Jersey, Prentice Hall, 2000.

BAKHTIN, M. Marxismo e filosofia da linguagem. São Paulo, Hucitec, 2002.

BARKER, C. W. \& ANSHEN M. Modern Marketing. New York, McGraw-Hill, 1939.

BARROS FILHO, C. Ética na Comunicação. São Paulo, Summus, 2003.

BAUDRILLARD, J. La société de consommation. Paris, 1990.

Para uma crítica da economia política do signo. Rio de Janeiro, Elfus, 1995.

BAUMAN, Z. Amor Líquido. Rio de Janeiro, Zahar, 2000.
. Ética pós-moderna. São Paulo, Paulus, 1997.

. Modernidade Líquida. Rio de Janeiro, Zahar, 2000

BOURDIEU, P. La distinction. Paris, Minuit, 1979.

CAMPBELL, C. A ética romântica e o espírito do consumismo moderno. Rio de Janeiro, Rocco, 2001.

CHAUI, M. O que é ideologia?, São Paulo, Brasiliense, 2003.

. Público, Privado, Despotismo. IN: Ética, org. Adauto Novaes, São Paulo, Cia das Letras, 2000.

COMTE-SPONVILLE, A. Traitè du désepoir de la beatitude. Tome 2, "Vivre", Paris, PUF, 1988.

di NALLO, E. Meeting Points. Cobra, São Paulo, 1999

EAGLETON, T. As ilusões do pós-modernismo. Rio de Janeiro, Zahar, 1998.

—_ La ideología y sus vicisitudes en el marxismo occidental. In: Ideología Un mapa de la cuestión (org: Slavoj Zizek), Buenos Aires, Fondo de Cultura Económica de Argentina, 2003.

ESPINOSA, B. Ética à maneira dos geômetras. São Paulo, Atena, s/d

FERRARI, F. Planejamento e atendimento. A arte do guerreiro. São Paulo, Loyola, 1997.

FROMM, E. The Psychological Aspects of the Guaranteed Income. In The Guaranteed Income: Next Step in Economic Evolution?, org. Robert Theobald, Nova York, Doubleday, 1964.

GIDDENS, A. The consequences of modernity - Palo Alto, Stanford University Press, 1990.

GOFFMAN, E. A Representação do Eu na Vida Cotidiana. Petrópolis, Vozes, 2003.

KAUFMANN, J-C. Ego. Paris, Nathan, 2001.

KOTLER, Ph. Personalização em massa. In HSM Management, N. 5, Nov/1997.

KUHN, T. A estrutura das revoluções científicas. São Paulo, Perspectiva, 2003.

JAMESON, F. Modernidade singular. Rio de Janeiro, Civilização brasileira, 2005. 
Jr. MARKIN, R. Consumer Behaviour: A Cognitive Orientation. Nova York, Macmillam, 1974.

LYOTARD, J-F. La Condition Post-Moderne. Paris, Minuit, 1979.

- Réponse à la question, qu'est-ce que le postmoderne?, In Le postmoderne expliqué aux enfants Paris, Seuil, 1986.

LIPOVETSKY, G. Os tempos hipermodernos. São Paulo, Barcarolla, 2004.

McCARTHY, J. Basic Marketing, Homewood. Richard Irwin, 1960.

MAFFESOLI, M. A Contemplação do Mundo.Porto Alegre, Ofícios, 1995.

MONGARDINI, C. Spazio sociale e cultura moderna. In Teoria sociológica stratificazione sociale. Roma, Nis, 1986.

O'NEILL, J. The Productive Body: An Essay on the Work of Consumption. In Queen's Quarterly, Nova York, 85, 1978.

PEREZ, C. Signos da Marca. São Paulo, Thomson, 2004

SANTOS, J. O que é pós-moderno? São Paulo, Brasiliense, 2004.

SÉBASTIEN, Ch. O individualismo paradoxal: introdução ao pensamento de Gilles Lipovetsky. In: Os tempos hipermodernos, Gilles Lipovetski, São Paulo, Barcarola.

SEIXAS, R. \& COELHO, P. Metamorfose Ambulante. In Raul Vivo, São Paulo, Eldorado, 1983.

SEMPRINI, A. Marche e mondi possibili. Un approccio semiotico al marketing della marca. Milano, Franco Angeli 